\title{
Enhanced transdermal delivery of lornoxicam by nanostructured lipid carrier gels modified with polyarginine peptide for treatment of carrageenan-induced rat paw edema
}

This article was published in the following Dove Press journal:

International Journal of Nanomedicine

\author{
Shanshan Gao \\ Baocheng Tian \\ Jingtian Han \\ Jing Zhang \\ Yanan Shi \\ Qingzhi Lv \\ Keke Li
}

School of Pharmacy, Binzhou Medical University, Yantai, People's Republic of china
Correspondence: Keke Li School of Pharmacy, Binzhou Medical University, 346 Guanhai Road, Yantai 264003, People's Republic of china

Tel +86535 6913406

Fax +865356913718

Email Like_tju@aliyun.com
Background: Nanostructured lipid carriers (NLCs) are emerging as attractive drug carriers in transdermal drug delivery. The surface modification of NLCs with cell-penetrating peptides (CPPs) can enhance the skin permeation of drugs.

Purpose: The objective of the current study was to evaluate the ability of the cell-penetrating peptide (CPP) polyarginine to translocate NLCs loaded with lornoxicam (LN) into the skin layers and to evaluate its anti-inflammatory effect.

Methods: The NLCs were prepared using an emulsion evaporation and low temperature solidification technique using glyceryl monostearates, triglycerides, DOGS-NTA-Ni lipids and surfactants, and then six histidine-tagged polyarginine containing 11 arginine (R11) peptides was modified on the surface of NLCs.

Results: The developed NLCs formulated with LN and R11 (LN-NLC-R11) were incorporated into $2 \%$ HPMC gels. NLCs were prepared with a particle size of $(121.81 \pm 3.61)-(145.72 \pm 4.78)$ $\mathrm{nm}$, and the zeta potential decreased from $(-30.30 \pm 2.07)$ to $(-14.66 \pm 0.74) \mathrm{mV}$ after the modification of R11 peptides. The encapsulation efficiency and drug loading were (74.61 $\pm 1.13) \%$ and $(7.92 \pm 0.33) \%$, respectively, regardless of the surface modification. Cellular uptake assays using HaCaT cells suggested that the NLC modified with R11 $(0.02 \%$, w/w) significantly enhanced the cell internalization of nanoparticles relative to unmodified NLCs $(P<0.05$ or $P<0.01)$. An in vitro skin permeation study showed better permeation-enhancing ability of $\mathrm{R} 11(0.02 \%, \mathrm{w} / \mathrm{w})$ than that of other content $(0.01 \%$ or $0.04 \%)$. In carrageenan-induced rat paw edema models, LN-NLC-R11 gels inhibited rat paw edema and the production of inflammatory cytokines compared with LN-NLC gels and LN gels $(P<0.01)$.

Conclusion: In our investigation, it was strongly demonstrated that the surface modification of NLC with R11 enhanced the translocation of LN across the skin, thereby alleviating inflammation. Keywords: lornoxicam, nanostructured lipid carriers, cell penetrating peptides, transdermal drug delivery, anti-inflammatory effect

\section{Introduction}

As a nonsteroidal anti-inflammatory drug (NSAID), lornoxicam (LN) has been used to treat various painful and inflammatory conditions and is thought to display effective analgesic and anti-inflammatory effects by selectively inhibiting cyclooxygenase-2 (COX-2).

The oral tablet and injection of LN are currently used widely to treat pain, rheumatoid diseases and inflammation. ${ }^{1,2}$ After oral administration, LN demonstrates 
poor solubility in the acidic conditions of the stomach because of its weak acidity, causing sustained contact with the stomach wall and dyspepsia, ulceration, and anorexia. Additionally, other side effects such as anemia, hepatitis and the first-pass effect may occur upon oral administration of $\mathrm{LN}^{3}$ Moreover, injection administration is inapplicable to chronic conditions because of its poor safety and compliance for patients. ${ }^{4}$

An alternative route to overcome the side effects may be the transdermal delivery route, which has been developed in the past few years. ${ }^{5,6}$ The transdermal application of drugs has been proven to contribute to avoiding first-pass metabolism and preventing gastrointestinal damage, further improving the safety profile and patient compliance. ${ }^{5-9}$ In transdermal drug delivery systems, the stratum corneum (SC), with the largest barrier function, decreases the absorptive amount of active drugs in the skin layers. ${ }^{10}$ It is important to ensure that a sufficient amount of active drugs enter the skin or remain in the skin. Additionally, the high active drug levels at specific sites of the skin is beneficial to improve the clinical efficacy in the treatment of inflammation. Therefore, to weaken the skin barrier and further enhance the skin permeation of drugs, several approaches have been developed in recent years, such as chemical ${ }^{11,12}$ and physical enhancement methods containing magnetophoresis, ${ }^{13}$ iontophoresis, ${ }^{14,15}$ electroporation, ${ }^{16}$ and microneedles, ${ }^{17}$ but their applications are limited because of therapeutic feasibility and toxicity.

An alternative method to enhance drug penetration through the skin is the application of nanoparticles, including solid lipid nanoparticles (SLNs), nanostructured lipid carriers (NLCs), liposomes and nanoemulsions. ${ }^{18,19}$ Among these, NLCs containing solid and liquid lipids have been developed as the second generation of lipid nanoparticles superior to SLNs. ${ }^{20}$ NLCs have been reported to load more drug and prevent it from being expulsed from the carrier because of the generally high solubility of drugs in liquid lipids. NLCs have been reported to demonstrate improved stability, controlled release mode of drugs and good biocompatibility. ${ }^{21,22}$ Additionally, NLCs can reduce the skin barrier and improve the lipid solubility of drugs, thus translating the drugs across the skin effectively, as well as protecting the active drugs from degradation. ${ }^{23}$ To our knowledge, LN can be incorporated in some carriers, such as transdermal patches, ${ }^{5}$ films, ${ }^{6}$ gels ${ }^{9,24,25}$ and $\mathrm{NLCs}^{8}$ for transdermal drug delivery. To further enhance the delivery of NLCs into deep skin layers, cell-penetrating peptides (CPPs) have been investigated for their ability to translocate nanoparticles across the cellular membrane when modified on the surface of NLCs. ${ }^{26}$ To improve the skin permeability of drugs, various CPPs, such as polyarginine (R8, R9 and R11) peptides, the transactivating transcriptional activator (TAT) peptide, penetratin (PEN) and polylysine-9 (K9), have been used. ${ }^{27-29}$ Among these, polyarginine peptides are widely used in transdermal drug delivery because of the membrane translocating capability produced by the interaction between the positive charges in arginine and negative charges in phospholipids of the cell membrane. Additionally, no study has specifically investigated the potential of polyarginine peptides modified with NLCs loaded with LN.

In the present study, we developed LN-NLCs (containing DOGS-NTA-Ni spacer) modified with six histidinetagged polyarginine peptides containing 11 arginines, abbreviated as R11. Additionally, the imidazole group in histidine can be specifically bound to the metal-ion-chelating lipid (DOGS-NTA-Ni). Furthermore, a suitable proportion of R11 was selected and assessed for cellular uptake and in vitro skin permeation experiments. Moreover, hydroxypropyl methylcellulose (HPMC) was used as matrices to prepare gel formulations for the application of LN-NLC-R11. The anti-inflammatory effect of LN-NLC-R11 gels was evaluated in the carrageenaninduced paw edema experiment accompanied with the analysis of the pro-inflammatory cytokines.

\section{Materials and methods Material}

LN was purchased from Hubin Pharmaceutical Raw Materials Co., Ltd. (Jiangsu, China). Soybean phospholipids were obtained from Tywei Pharmaceutical Co., Ltd. (Shanghai, China). 1,2-Dioleoyl-sn-glycero-3-[(N-(5-amino-1-arboxypentyl) imidodiacetic acid) succinyl nickel salt] (DOGSNTA-Ni) was provided by Avanti Polar lipids (AL, USA). The six histidine tagged polyarginine peptides (R11: 6 histidine tag-RRRRRRRRRRR) were obtained from China Peptides Co., Ltd. (Shanghai, China). Diclofenac sodium gels were purchased from Health Pharmaceutical Co., Ltd. (Shandong, China). Distilled water was used in the experiment.

\section{Animals}

The BALB/c mice (eight-week-old) and Sprague-Dawley rats (180-200 g) provided by the Animal Center of Luye 
Pharma Group (Yantai, China) were used in the experiment. The experimental animals were maintained in laboratory conditions (temperature of $20 \pm 3{ }^{\circ} \mathrm{C}$ and humidity of $60 \pm 5 \%$ ) for at least a week and were free to food and water. Animal study was performed in accordance with the guidelines of Institutional Animal Care and National Institutes of Health Guide for the Care and Use of Laboratory Animals (USA), and the protocol was approved by the Committee on the Ethics of Animal Experiments of Binzhou Medical University (Permit No. SCXK20140005).

\section{Preparation of nanoparticles}

LN-NLCs were prepared using an emulsion-evaporation and low temperature solidification method. Briefly, LN (7.5 mg), glyceryl monostearate $(270 \mathrm{mg})$, triglycerides (90 mg), soy lecithin (150 mg), DOGS-NTA-Ni (6 mg) and Tween $80(720 \mathrm{mg})$ were dissolved in methanol and then were heated at $80^{\circ} \mathrm{C}$ in a water bath with continuous stirring. An aqueous surfactant solution was prepared by dissolving poloxamer 188 (240 mg) in water, followed by heating at $80{ }^{\circ} \mathrm{C}$. Next, aqueous solution was added to the hot lipid phase under a stir rate of $600 \mathrm{rpm}$ to obtain the final mixture $(30 \mathrm{~mL})$. The obtained mixture was stirred for $40 \mathrm{~min}$ at $80{ }^{\circ} \mathrm{C}$ to strengthen the emulsification and evaporate the residual methanol. Thereafter, LN-NLCs were obtained by solidifying the nanoemulsions in an ice water bath for $1 \mathrm{~h}$.

NLCs labeled with the fluorescent dye rhodamine B (RhB-NLCs) were prepared. RhB $(0.02 \% \mathrm{w} / \mathrm{w})$ was added to the lipid phase in the absence of LN. The finally obtained NLC dispersion was dialyzed against ultrapure water for $24 \mathrm{~h}$ using a dialysis sack $(\mathrm{MWCO}=1000)$ with regular water replacement to remove free $\mathrm{RhB}$.

For surface modification, freshly prepared LN-NLCs were mixed with $5 \mathrm{mg} / \mathrm{mL}$ of 6 histidine-tagged R11 water solution in various ratios of DOGS-NTA-Ni and 6 histidine-tagged R11 (2:1, 1:1 and 1:2). The mixtures were incubated for $3 \mathrm{~h}$ at room temperature with constant stirring to obtain LN-NLC-R11.

\section{Characterization of nanoparticles}

\section{Determination of particle size and zeta potential}

The particle size and polydispersity indices (PDI) of LN-NLC (with or without R11) were measured in distilled water by dynamic light scattering (DLS) using Zetasizer (Malvern, Nano-ZS, UK). The zeta potential was determined in clear disposable zeta cell.

\section{Surface morphology}

The surface morphology of LN-NLC-R11 and NLC-R11 were measured by transmission electron microscopy (TEM; JEM-1230, JEOL, Japan). The suspensions were diluted and placed on a membrane-coated carbon grid surface. After staining with $1 \%$ phosphotungstic acid for $1 \mathrm{~min}$, the grid surface was air dried and examined by TEM.

\section{Entrapment efficiency of LN-NLC samples}

The encapsulation efficacy and drug-loading percentages in LN-NLC and LN-NLC-R11 were determined by ultrafiltration using vivaspin columns with a filter membrane (MWCO $=10,000 \mathrm{Da}$; Millipore, USA). The LN-NLC suspensions were diluted 50 times in phosphate buffer ( $\mathrm{pH}$ 7.40), and subsequent dilutions were added to the donor compartment of the vivaspin columns to separate the unencapsulated drug from NLC at $4{ }^{\circ} \mathrm{C}$ and $6000 \mathrm{r} / \mathrm{min}$ for 20 min using a centrifuge (LR16-A; LAB Centrifuge Co., Ltd., China). The weight of free drug $\left(\mathrm{W}_{\text {free }}\right)$ was obtained according to the concentration of free drug in the receiver compartment. To determine the total amount of drug present in NLCs, $1 \mathrm{~mL}$ of LN-NLC suspension was dissolved in $10 \mathrm{~mL}$ of methanol via an ultrasonic machine (KQ52003; Kunshan Shumei Ultrasonic Instrument Co., Ltd., China) for $20 \mathrm{~min}$, and subsequent dilutions were made with methanol. The total weight of drug $\left(\mathrm{W}_{\text {total }}\right)$ in the methanol solution and weight of free drug were determined using an UV-spectrophotometer (TU-1901; Beijing Persee General Instrument Co., Ltd., China) at a wavelength of $378 \mathrm{~nm}$. The entrapment efficiency (EE) the drug loading percentage (DL) were calculated as follows:

$$
\begin{gathered}
\mathrm{EE} \%=\left(1-\mathrm{W}_{\text {free }} / \mathrm{W}_{\text {total }}\right) \times 100 \% \\
\mathrm{DL} \%=\left(\mathrm{W}_{\text {total }}-\mathrm{W}_{\text {free }}\right) / \mathrm{W}_{\text {lipid }} \times 100 \%
\end{gathered}
$$

$\mathrm{W}_{\text {lipid }}$ : the weight of total materials used in NLC.

\section{Differential scanning calorimetry (DSC) analysis}

To investigate the crystallization behavior of samples, DSC analysis was carried out using a differential scanning calorimeter (TGA/DSC 3+; METTLER TOLEDO, Germany) with a STARe Software System. An appropriate amount (approximate $5 \mathrm{mg}$ ) of pure LN, pure glyceryl monostearate and lyophilized LN-NLCs developed in this study were placed in an alumina crucible (METTLER TOLEDO, Germany). The temperature was then heated from 30 to $300{ }^{\circ} \mathrm{C}$ with a heating rate of $10 \mathrm{~K} \cdot \mathrm{min}^{-1}$ and a nitrogen flow of $20 \mathrm{~mL} \cdot \mathrm{min}^{-1}$. 


\section{Preparation of gels}

The exact amount of HPMC ( $2 \%)$ was dispersed in warm water with continuous stirring. Next, the LN suspensions $(0.05 \%$ of $\mathrm{LN}, \mathrm{w} / \mathrm{w})$ were added slowly into the dispersion of HPMC with continuous stirring to obtain homogeneous dispersion, and $\mathrm{LN}$ gels (containing $0.045 \% \mathrm{LN}$ ) were obtained after being kept in the dark overnight to allow complete swelling. The LN-NLC gels and LN-NLC-R11 gels (equivalent to $0.045 \% \mathrm{LN}$ ) were obtained by LN-NLC and LN-NLC-R11 dispersion, respectively, and not the LN suspensions. Additionally, blank NLC gels were prepared without LN.

\section{Physicochemical and rheological characterization of gels}

The developed LN-NLC-R11 gels, LN-NLC gels and LN gels were characterized by their appearance, homogeneity, $\mathrm{pH}$ and rheological property. The appearance and homogeneity of the gels were inspected visually. ${ }^{30}$

The $\mathrm{pH}$ of the gels was measured using a $\mathrm{pH}$ meter (EL20; Mettler Toledo, USA) after diluting the gels (1 g) in $20 \mathrm{~mL}$ of distilled water. ${ }^{31}$

The viscosity of LN-NLC-R11 gels was determined using a digital viscometer (SNB-1; Shanghai Hengping Instrument Co. Ltd, Shanghai, China) at room temperature and varying the shear speeds $(6-60 \mathrm{rpm})$ with a number 4 spindle. The rheological property of the gels was described by the flow curve of the viscosity versus shear speed.

\section{Stability studies of gels}

The stability test was performed to investigate the stability of LN-NLC-R11 gels. Three batches of LN-NLC-R11 gels were packed into tubes (with plugs) and stored at room temperature for one month. The samples were then observed periodically for changes in appearance, homogeneity, $\mathrm{pH}$ and viscosity.

\section{In vitro cellar uptake study} Cell culture

Human hyperproliferative keratinocyte (HaCaT) cell lines were purchased from the $\mathrm{BeNa}$ Culture Collection (Beijing, China). The cells were cultured in Dulbecco's modified Eagle's medium (DMEM) (high glucose) with $10 \%(\mathrm{v} / \mathrm{v})$ fetal bovine serum (FBS) at $37{ }^{\circ} \mathrm{C}$ and in a $5 \%$ $\mathrm{CO}_{2}$ atmosphere.

\section{Cytotoxicity study}

The cytotoxicity of NLC, LN-NLC, NLC-R11 and LNNLC-R11 to HaCaT cells was determined utilizing the
MTT (3-(4,5-dimethylthoazol-2yl)-2,5-diphenyl-2H-tetrazolium bromide) assay. $\mathrm{HaCaT}$ cells were seeded in a 96well plate at a density of 10,000 cells/well and were allowed to incubate with different formulations at various concentrations of $\mathrm{LN}$ for $72 \mathrm{~h}$ at $37^{\circ} \mathrm{C}$. Next, the cells were washed with PBS (pH 7.4) and cultured with fresh DMEM (no FBS) containing MTT for $4 \mathrm{~h}$ at $37{ }^{\circ} \mathrm{C}$, and then the culture medium was removed and replaced with $200 \mathrm{~mL}$ of DMSO to dissolve the formazan crystals in cells. The plate was shaken for $10 \mathrm{~min}$ in the dark. The absorbance was measured at $490 \mathrm{~nm}$ using a microplate spectrophotometer (SpectraMax M2; Molecular Devices, Sunnyvale, CA, USA). To obtain a background reference, wells without seeded cells were employed, and control wells were obtained using cells treated without samples. The cell viability was calculated as follows:

$$
\text { Cell viability }(\%)=\left(A_{t}-A_{b}\right) /\left(A_{c}-A_{b}\right) \times 100 \% \text {. }
$$

Where $A_{t}, A_{b}$ and $A_{c}$ are the absorbance of tested samples, background reference and control wells, respectively.

\section{In vitro cellar uptake study}

Flow cytometry (FCM)

The in vitro cellar uptake assay of RhB-NLC and RhBNLC-R11 (the method of preparation was as described in Preparation of nanoparticles) was studied in $\mathrm{HaCaT}$ cells by flow cytometry. Cells were seeded at a density of $5 \times 10^{4}$ cells/well in six-well culture plates and were cultured overnight. Next, the cells were incubated with different formulations (equivalent to $6 \mu \mathrm{g} / \mathrm{mL}, 12 \mu \mathrm{g} / \mathrm{mL}$ and $25 \mu \mathrm{g} /$ $\mathrm{mL}$ of $\mathrm{RhB}$ ) for 1,2 and $4 \mathrm{~h}$ at $37^{\circ} \mathrm{C}$. After coculture, cells were washed with phosphate-buffered saline (PBS, $\mathrm{pH}$ 7.4) to remove extracellular particles. The associated fluorescence in cells was determined using flow cytometry (Epics XL; Beckman Coulter, Brea, CA, USA) at an excitation wavelength of $530 \mathrm{~nm}$ and an emission wavelength of $590 \mathrm{~nm}$.

Additionally, the connection of the peptide (six histidine-R11 peptide) to DOGS-NTA-Ni was determined by flow cytometry. Briefly, cells were incubated with RhBNLC-R11 and RhB-NLC (no DOGS-NTA-Ni) mixed with R11 for $2 \mathrm{~h}$. After incubation, the cells were washed with PBS ( $\mathrm{pH}$ 7.4) and the associated fluorescence was determined using flow cytometry.

\section{Confocal laser scanning microscopy (CLSM)}

Confocal laser scanning microscopy (CLSM) was employed to observe the location of RhB-NLC and RhB-NLC-R11 in 
HaCaT cells. HaCaT cells were seeded in six-well plates at a density of $5 \times 10^{4}$ cells/well. Next, the cells were cultured with different samples (equivalent to $6 \mu \mathrm{g} / \mathrm{mL}, 12 \mu \mathrm{g} / \mathrm{mL}$ and $25 \mu \mathrm{g} / \mathrm{mL}$ of $\mathrm{RhB}$ ). After incubation for 1,2 , and $4 \mathrm{~h}$ at $37{ }^{\circ} \mathrm{C}$, the cells were fixed with paraformaldehyde, and Hoechst $33342(10 \mathrm{mg} / \mathrm{mL})$ was used to stain cell nuclei. $\mathrm{HaCaT}$ cells were then subjected to confocal laser scanning microscopy (TCS SPE; Leica Microsystems, Wetzlar, Germany) at an excitation wavelength $530 \mathrm{~nm}$ and an emission wavelength of $590 \mathrm{~nm}$.

\section{Mechanism of RII as a penetration enhancer}

The mechanism of the cell uptake of R11 was investigated in $\mathrm{HaCaT}$ cells by determining the concentration of $\mathrm{Ca}^{2+}$ and change in the membrane potential.

Measurements of the membrane potential in $\mathrm{HaCaT}$ cells The membrane potential in HaCaT cells was monitored using the fluorescence dye bis-(1,3-dibutylbarbituric acid) trimethine oxonol [DiBAC4 (3)] (Dojindo, Kumamoto, Japan), which was sensitive to the membrane potential. Briefly, the cells were cultured with LN-NLC $(12 \mu \mathrm{g} / \mathrm{mL})$ and LN-NLC-R11 $(12 \mu \mathrm{g} / \mathrm{mL})$ for $24 \mathrm{~h}$ in an incubator at $37{ }^{\circ} \mathrm{C}$ and $5 \% \mathrm{CO}_{2}$. Next, the cells were digested with pancreatin and were washed with PBS to remove the samples. The solution of DiBAC4 (3) $(5 \mu \mathrm{g} / \mathrm{mL})$ was added and incubated with the cells for $0.5 \mathrm{~h}$. The mean fluorescence intensity was measured using flow cytometry (Epics XL; Beckman Coulter, Brea, CA, USA) at an excitation wavelength of $488 \mathrm{~nm}$ and an emission wavelength of $530 \mathrm{~nm}$. Cells without treatment were used as zero adjustment.

\section{Measurement of the $\mathrm{Ca}^{2+}$ concentration of $\mathrm{HaCaT}$ cells} The changes in the intracellular $\mathrm{Ca}^{2+}$ concentration were determined using the calcium-sensitive fluorescent probe derivative fluo-3 AM, which easily penetrates cell membranes. Fluo-3 AM is cleaved by esterase in cells to fluo-3, which presents bright fluorescence after combining $\mathrm{Ca}^{2+.32}$ The fluorescence intensity of the cells cultured with LNNLC $(12 \mu \mathrm{g} / \mathrm{mL})$ or LN-NLC-R11 $(12 \mu \mathrm{g} / \mathrm{mL})$ was measured by flow cytometry (Epics XL; Beckman Coulter, Brea, CA, USA) at excitation wavelength of $488 \mathrm{~nm}$ and an emission wavelength of $525 \mathrm{~nm}$, and cells without treatment were used as the blank control. Briefly, after the incubation of cells with LN-NLCs and LN-NLC-R11 for $24 \mathrm{~h}$ at $37{ }^{\circ} \mathrm{C}$ and $5 \% \mathrm{CO}_{2}$, the cells were washed 3 times with PBS. Next, the cells were incubated in culture medium containing Fluo-3 AM $(5 \mu \mathrm{mol} / \mathrm{L})$ for $0.5 \mathrm{~h}$. The intracellular fluorescence intensity was measured using flow cytometry.

\section{In vitro skin permeation studies Preparation of the isolated skin of mice}

The mice were sacrificed by cervical dislocation, and abdominal hairs were removed carefully using an electric shaver. The skin from the abdominal surface was excised, and the adherent fat and subcutaneous tissue were removed carefully. Next, the isolated skin was washed with phosphate-buffered saline (PBS, $\mathrm{pH}$ 7.40), and its integrity was assured during the experiment.

\section{In vitro skin permeation studies}

The percutaneous permeability of LN-NLCs and LNNLCs loaded with various amounts of cell penetrating peptide R11 $(0.01 \%, 0.02 \%$ and $0.04 \%$ respectively) was investigated in in vitro skin permeation studies using the Franz diffusion method.

Briefly, $1 \mathrm{~mL}(0.75 \mathrm{mg}$ of LN) of LN-NLC or R11coated LN-NLC formulations was applied onto the stratum corneum (SC), which faced the donor compartment of Franz diffusion cells. The receptor chamber was filled with $16 \mathrm{~mL}$ of PBS ( $\mathrm{pH} 7.40)$ under the condition of $400 \mathrm{r} / \mathrm{min}$ and $37 \pm 0.5{ }^{\circ} \mathrm{C}$ to maintain the physiological activity of the skin. The occlusive condition was sustained to prevent water from evaporating throughout the experiment. To draw the percutaneous permeability curve, all receiver fluid was collected and the fresh PBS ( $\mathrm{pH} 7.40)$ with an equal volume and temperature was added directly into the receptor compartment at predetermined time intervals. The content of $\mathrm{LN}$ in receiver fluid was measured using HPLC (Agilent 1260) and the cumulative amount of permeated LN was calculated as follows.

$$
\mathrm{Q}=\frac{\sum_{\mathrm{i}=1}^{\mathrm{n}} \mathrm{C}_{\mathrm{n}} \times \mathrm{V}}{\mathrm{A}}
$$

Here, $\mathrm{Q}\left(\mu \mathrm{g} / \mathrm{cm}^{2}\right)$ is the cumulative penetration amount per $\mathrm{cm}^{2}, \mathrm{C}_{n}(\mu \mathrm{g} / \mathrm{mL})$ is the LN concentration of the $n$th sample, $\mathrm{V}(\mathrm{mL})$ is the volume of the receiver fluid, and A $\left(\mathrm{cm}^{2}\right)$ is the infiltrating area.

\section{Drug extraction from the skin}

After $24 \mathrm{~h}$ of skin permeation, the fluid in the receptor compartment was collected, and the surface of the mouse skin was washed carefully with PBS ( $\mathrm{pH}$ 7.4) to remove excess formulations and sucked dry. Thereafter, the mouse skin dosing area was cut off and then cut into pieces to a mixture with $0.4 \mathrm{~mL}$ of PBS (pH 7.4). After 
homogenization in the vortex, $0.6 \mathrm{~mL}$ of methanol was added to the mixture. The mixture was then disposed using an ultrasonic cell disruptor (Scientz-II D; Ningbo Scientz Biotechnology Co., Ltd., China) for $10 \mathrm{~min}$ to destroy skin tissue maximally. Subsequently, the mixture was centrifuged at $13,500 \mathrm{rpm}$ for $10 \mathrm{~min}$ to collect the supernatant, and then the residues were mixed again with $0.5 \mathrm{~mL}$ of methanol, homogenized and subjected to centrifugation as described above. After 3 rounds of homogenization and centrifugation, the total supernatant was analyzed using HPLC to determine the drug content, and the skin deposition of LN per unit area $Q_{\mathrm{s}}\left(\mu \mathrm{g} / \mathrm{cm}^{2}\right)$ was calculated

\section{HPLC analysis}

HPLC analysis of LN was performed using a reversedphase C18 analytical column $(5 \mu \mathrm{m} ; 4.6 \times 250 \mathrm{~mm})$ and an ultraviolet (UV)-visible variable wavelength detector. The mobile phase comprised methanol, and an aqueous solution containing $0.05 \%$ trimethylamine $(52: 48, \mathrm{v} / \mathrm{v})$ was used to detect $\mathrm{LN}$, with a flow rate of $1.0 \mathrm{~mL} / \mathrm{min}$. The drugs in the samples were detected at a column temperature of $25{ }^{\circ} \mathrm{C}$, an injection volume of $20 \mu \mathrm{L}$ and a wavelength of $378 \mathrm{~nm}$.

\section{Skin irritation test}

Six New Zealand white rabbits were used to evaluate the skin irritation potential of LN-NLC-R11 gels. Hairs on the backside area of rabbits were removed by hair clippers $24 \mathrm{~h}$ prior to experiment. LN-NLC-R11 gels were smeared uniformly on the left side of hairless skin once a day for 7 days, and no treatment was carried out on the right side of hairless skin. The skin was observed for any response, including redness and erythema, after the application of LN-NLC-R11 gels. In the skin irritation test, we referred to the scoring criteria in the literatures. ${ }^{33,34}$ The scores of erythema and edema were recorded (ranging from 0 to 4 ), and the scores were called as the irritation index. It was calculated to evaluate the degree of irritation. An irritation index below 0.4 indicates negligible irritation.

\section{In vivo anti-inflammatory activity of the formulations of LN \\ Experimental design to analyze pharmacological activity}

Before the implementation of the experiment, 40 healthy Sprague-Dawley rats were discretionarily sectionalized into 5 groups $(\mathrm{n}=8)$. These groups were administered either blank NLC gels (A, negative control), diclofenac sodium gels (B, positive control), LN gels (C), LN-NLC gels (D) and LN-NLC-R11 gels (E). The dose of drug administered to mice was $2 \mathrm{mg} / \mathrm{kg}$ in every group.

\section{Carrageenan-induced rat paw edema test}

The study of paw edema induced by carrageenan was carried out to explore the anti-inflammatory activity of different formulations. Prior to $1 \mathrm{~h}$ subcutaneous injection of carrageenan $(1 \% \mathrm{w} / \mathrm{v})$ with $0.1 \mathrm{~mL}$ into the middle part of the right hind paw, the samples were smeared on the right hind paw at an established dosage every $1 \mathrm{~h}$ for $3 \mathrm{~h}$. The paw volume at the marked position was measured using a toe volume meter (PV-200; Chengdu Techman Software Co., Ltd, China) at $0,1,2,3,4,5,6$ and $7 \mathrm{~h}$ after the application of $1 \%$ carrageenan. Paw edema was presented as an average increase in the paw volume at certain positions.

\section{Estimation of pro-inflammatory cytokines and chemokines in rat serum}

At the period of severe inflammation $(3 \mathrm{rd} \mathrm{h}$ of the experiment), blood samples from the rats were collected and serum was obtained by centrifugation (3K15; Sigma, Germany) at 2,000 rpm for $20 \mathrm{~min}$ at $4{ }^{\circ} \mathrm{C}$. The serum was stored at $-80{ }^{\circ} \mathrm{C}$ before determination, and the levels of IL-6, cyclooxygenase- 2 (COX-2) and inducible nitric oxide synthase (INOS) in rat serum were determined using enzyme-linked immunosorbent assay (ELISA) (Shang Hai Lengton Bioscience Co., LTD, China). ${ }^{35}$

\section{Statistical analysis}

One-way analysis variance (ANOVA) followed by the Fisher's least significant difference (LSD) test was used to compare two different groups of samples using SPSS version 19.0 software (IBM Corp., Armonk, NY, USA). Additionally, the data were expressed as the means \pm standard deviation. A $P$-value $<0.05$ was considered to indicate a significant difference between groups.

\section{Results and discussion}

\section{Characterization of nanoparticles and gels Characterization of nanoparticles}

The mean particle size of LN-NLCs was found to be 121.81 $\pm 3.61 \mathrm{~nm}$, with a polydispersity index (PDI) of $0.26 \pm 0.01$. The mean particle size of LN-NLC-R11 was increased to 145.72 $\pm 4.78 \mathrm{~nm}$ (with a PDI of $0.27 \pm 0.01$ ) because of the surface 
modification of LN-NLCs (Figure 1A). The zeta potential of LN-NLCs in double-distilled water was $-30.30 \pm 2.07 \mathrm{mV}$ and further decreased to $-14.66 \pm 0.74 \mathrm{mV}$ (Figure 1B) after surface modification with R11 because of the positive charges of the guanidine group in poly-arginines. The zeta potential is often considered to indicate whether poly-arginines have been

(A-1)

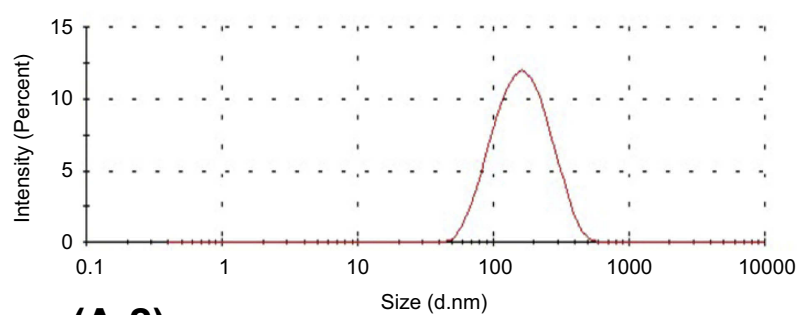

(A-2)

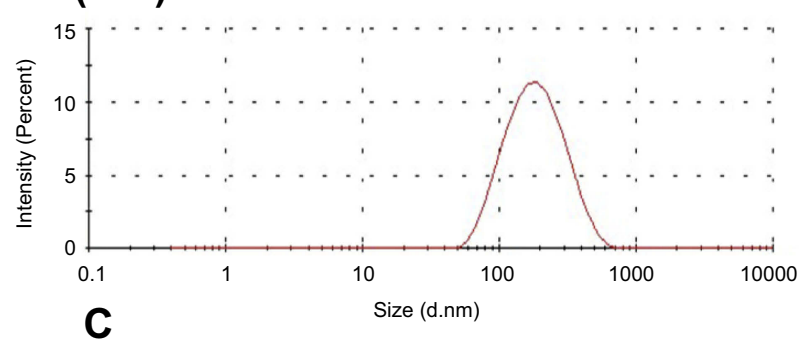

C

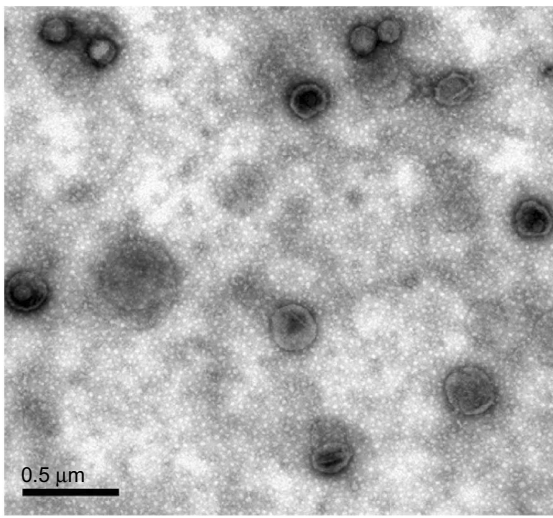

E

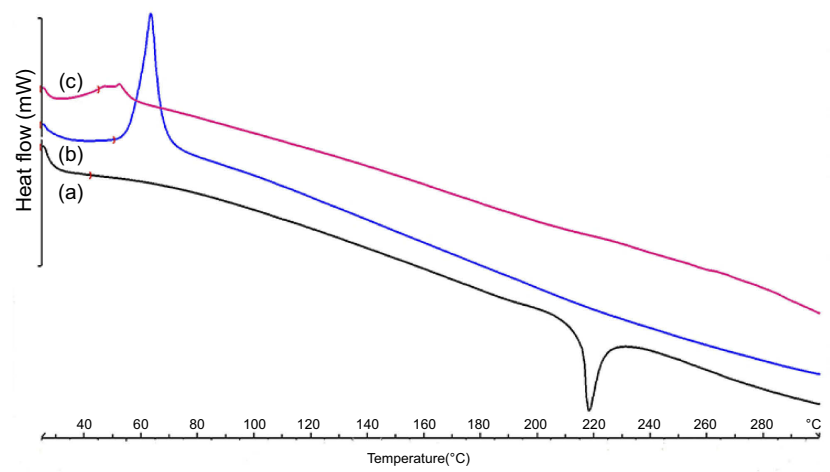

modified on the surface of nanoparticles because the zeta potential of the nanoparticles turns positive when poly-arginines are successfully modified. ${ }^{36,37}$

The images (Figure 1C) confirmed the formation of uniformly spherical particles regardless of the surface modification.

\section{(B-1)}
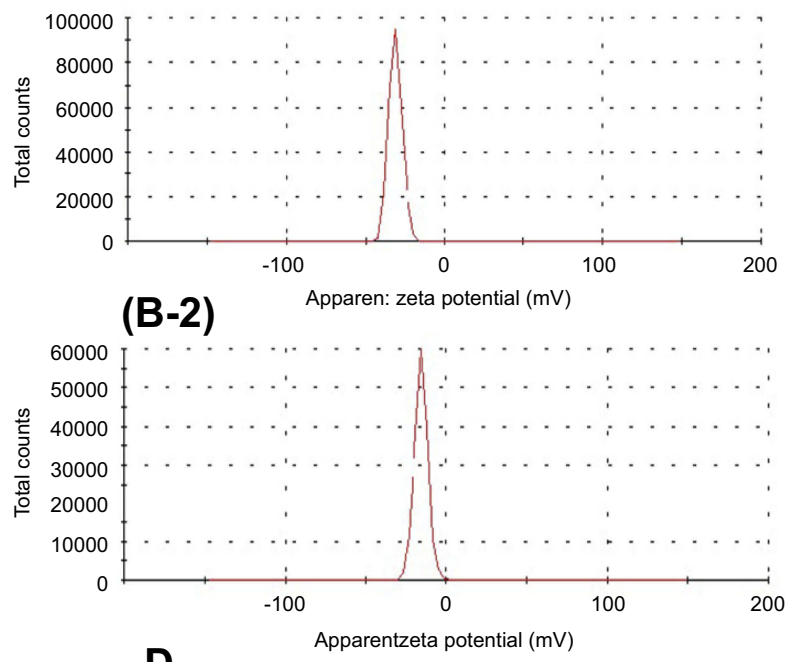

D

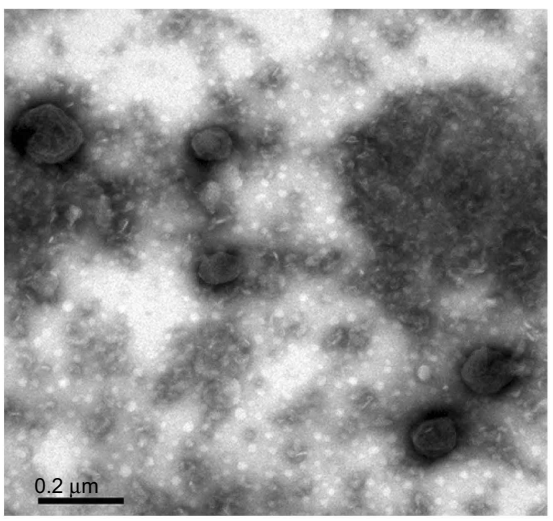

$\mathbf{F}$

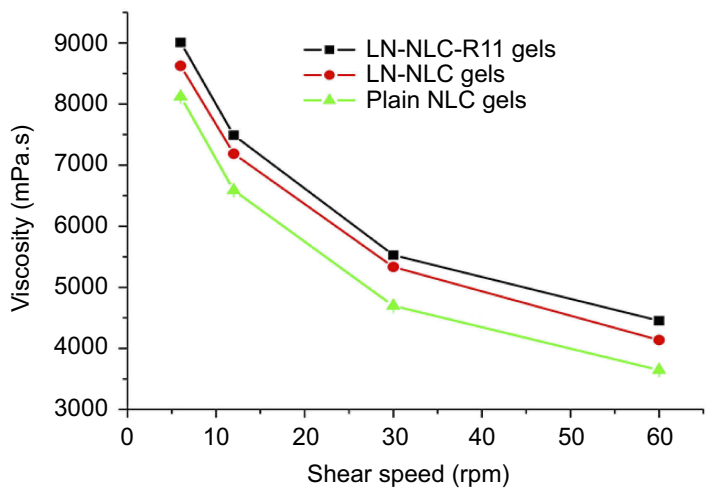

Figure I Pharmaceutical characterization of nanoparticles and gels.

Notes: (A-I), (A-2) Size distribution of LN-NLC and LN-NLC-RII, respectively; (B-I), (B-2) Zeta potential distribution of LN-NLC and LN-NLC-RII, respectively; (C and D) TEM imagines of LN-NLC-RI I and NLC-RI I; (E) DSC thermograms of LN (A), glyceryl monostearate (B) and LN-NLC (C); (F) Flow curves of formulation gels. Data presented as mean $\pm S D(n=3)$. 
The entrapment efficiency of LN in LN-NLCs was (74.61 $\pm 1.13) \%$, and the drug-loading percentage was $(7.92 \pm 0.33)$ $\%$. The entrapment efficiency and drug loading percentages of LN in LN-NLCs were unaffected by surface modification.

The thermodynamic properties of LN, glyceryl monostearate and LN-NLCs were analyzed by DSC, and the DSC thermograms of different formulations are shown in Figure 1E. A single endothermic peak at $219{ }^{\circ} \mathrm{C}$ was observed in the DSC curve of LN, which agrees with its melting point, and the crystalline nature of $\mathrm{LN}$ was confirmed. The exothermal peak of glyceryl monostearate was found at $63{ }^{\circ} \mathrm{C}$. Moreover, the melting endotherm of LN does not occur in the DSC thermogram of LN-NLC, indicating that the drugs were encapsulated completely inside the lipid matrix of NLCs in the amorphous form.

\section{Pharmaceutical characterization of gels}

The formulation gels prepared in this study presented slightly opaque and good homogeneity.

The $\mathrm{pH}$ values of $\mathrm{LN}$ formulation gels were in the range of 7.0-7.2, which would likely not produce irritation. Thus, they were considered suitable for skin application. ${ }^{38}$

The rheological properties of gels are closely related to the ease of application to the skin by affecting the adhesion and retention for topical application. The viscosities of LN-NLCR11 gels $(4452 \pm 12 \mathrm{mPa} \cdot \mathrm{s})$ and LN-NLC gels $(4136 \pm 8 \mathrm{mPa} \cdot \mathrm{s})$ were higher than those of $\mathrm{LN}$ gels $(3645 \pm 8 \mathrm{mPa} \cdot \mathrm{s})$ at a constant shear speed of $60 \mathrm{rpm}$. The cause might be that the incorporation of nanoparticles into the gel base increased the viscosity of gels. ${ }^{39}$ The flow curves shown in Figure $1 \mathrm{~F}$ indicated that the gels revealed a nonnewtonian, pseudo plastic flow pattern (increasing shear speed with a decrease in viscosity), maximizing the area coverage on application. Thus, it is an important characteristic for topical formulations. ${ }^{40,41}$

\section{Stability studies of gels}

As shown in Table 1, the LN-NLC-R11 gels were found to be stable at room temperature for one month, no stratification was observed, and the appearance of LN-NLC-R11 gels was still slightly opaque with good homogeneity. No significant change was observed in the $\mathrm{pH}$ and viscosity of gels, indicating that the LN-NLC-R11 gels developed in this study had good storage stability at room temperature for one month.

\section{Cytotoxicity of nanoparticles}

The cytotoxicity of NLC, LN-NLC, NLC-R11 and LN-NLCR11 on HaCaT cells was evaluated by MTT assays. As demonstrated in Figure 2, the blank NLC formulations resulted in cell viabilities greater than $90 \%$, indicating that the blank NLC had good biocompatibility to HaCaT cells before and after R11 peptide coating. Upon LN loading, the cell viability decreased as the $\mathrm{LN}$ concentration increased, and LN-NLCs coated with R11 peptide presented lower cell viability than uncoated LN-NLCs because of the enhanced cell permeability of the R11 peptide.

\section{In vitro cellar uptake study Flow cytometry}

Flow cytometry experiments were carried out to quantify the intracellular accumulation of samples. Figure 3 shows the accumulation of RhB-NLC-R11 in cells in the presence of various amounts of $\mathrm{R} 11$. When the cells were exposed to RhB-NLC-R11, the fluorescence intensity in cells was higher than that in cells exposed to RhB-NLC, indicating that the DOGS-NTA-Ni spacer $(0.02 \%$ in NLC, w/w) is on the surface of NLCs, resulting in the increased R11 peptide binding affinity to NLCs. Moreover, when the ratio of R11 to DOGSNTA-Ni was $1: 1(\mathrm{w} / \mathrm{w})$, the fluorescence intensity was higher than that of the other two ratios (1:2 or $2: 1)$. The results indicated that a further increase in the R11 content did not induce a further increase in the fluorescence intensity in cells. Moreover, no obvious increase in the fluorescence intensity in cells was observed after the coincubation of cells with RhB-NLCs mixed with R11 without the DOGS-NTA-Ni spacer, indicating no specific interaction between NLCs and the R11 peptide (Figure 3A-C). Therefore, the ratio (1:1 w/ w) of DOGS-NTA-Ni to the R11 peptide was adopted in further studies.

Table I Stability studies of LN-NLC-RII gels at room temperature for one month

\begin{tabular}{|l|l|l|l|l|}
\hline Parameter & $\mathbf{0 ~ d}$ & $\mathbf{1 0 ~ d}$ & $\mathbf{2 0} \mathbf{d}$ & $\mathbf{3 0} \mathbf{d}$ \\
\hline Appearance & Slightly opaque & Slightly opaque & Slightly opaque & Slightly opaque \\
Homogeneity & Good & Good & Good & Good \\
$\mathrm{pH}$ & $7.09 \pm 0.04$ & $7.08 \pm 0.02$ & $7.10 \pm 0.04$ & $7.11 \pm 0.03$ \\
Viscosity (mPa s) & $4452 \pm 12$ & $4450 \pm 11$ & $4447 \pm 11$ & $4443 \pm 10$ \\
\hline
\end{tabular}

Notes: Data presented as mean \pm SD $(n=3)$. 


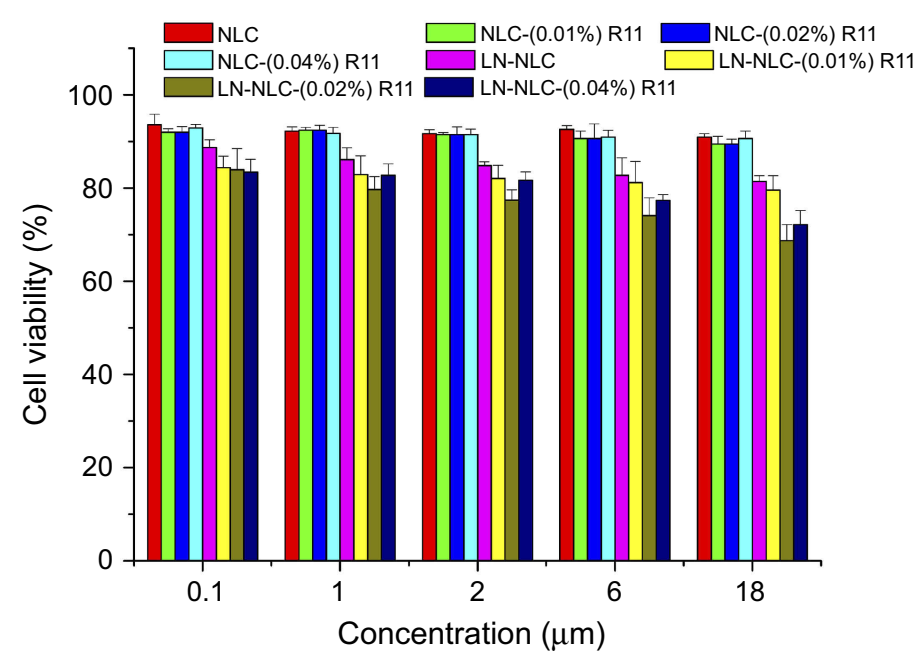

Figure 2 Cell viability of $\mathrm{HaCaT}$ cells incubated with different formulations with different concentration of LN for $72 \mathrm{~h}$.

Notes: The concentration of NLC without LN was calculated corresponding with LN-NLC. Data presented as mean \pm SD ( $n=3)$.

A

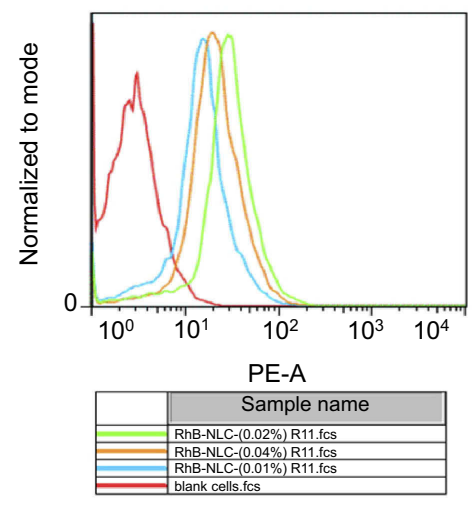

D

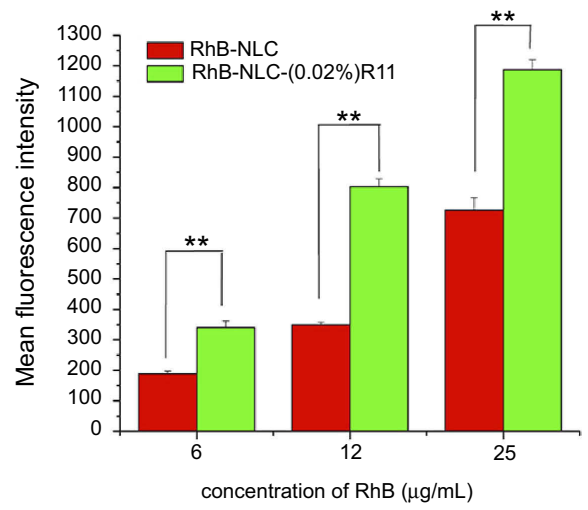

B

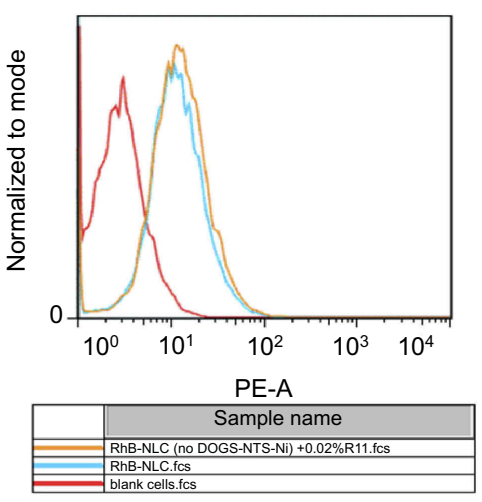

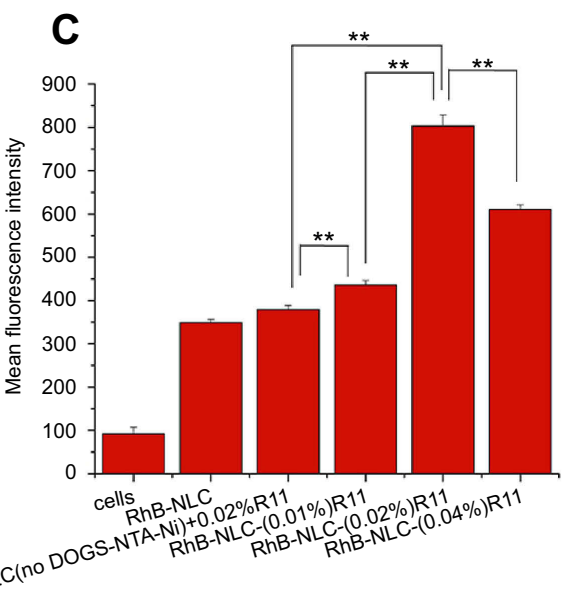

$\mathbf{E}$

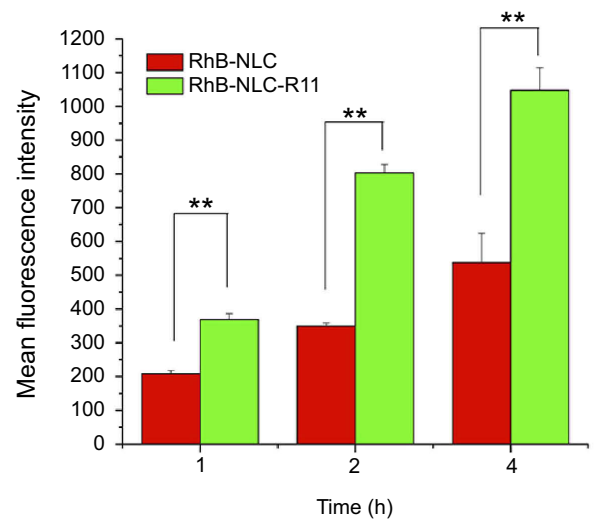

Figure 3 Cell uptake of different formulations in $\mathrm{HaCaT}$ cells analyzed by flow cytometry.

Notes: Flow-cytometry analysis (A and B) mean fluorescence intensities (C) of different formulations in HaCaT cells. (D and E) Mean fluorescence intensities of RhB-NLC and RhB-NLC-(0.02\%) RII incubated with $\mathrm{HaCaT}$ cells in various concentrations and time. $* * \mathrm{P}<0.0 \mathrm{I}$. Data presented as mean \pm SD ( $=3$ ). 
As shown in Figure 3D and E, the mean fluorescence intensity (MFI) inside $\mathrm{HaCaT}$ cells increased with a longer time and higher concentrations, demonstrating that $\mathrm{HaCaT}$ cells showed time-dependent and concentration-dependent uptake of RhB-NLCs with or without R11. Additionally, the results in Figure 3 $\square$ D and E) showed that the MFI of $\mathrm{HaCaT}$ cells treated with RhB-NLC-R11 was much higher than that of cells treated with RhB-NLCs at each time or concentration point.

\section{Confocal laser scanning microscopy imaging}

The uptake effect of RhB-NLC-R11 in HaCaT cells was visualized using CLSM. As shown in Figure 4, Hoechst 33342-stained nuclei appeared blue, and RhB labeled NLC (R11) appeared red. Higher rhodamine fluorescence intensity was observed at longer incubation times ( $1 \mathrm{~h}$ to $4 \mathrm{~h}$ ) and higher concentrations of rhodamine $(6 \mu \mathrm{g} / \mathrm{mL}$ to $25 \mu \mathrm{g} / \mathrm{mL})$ (Figure 4). As shown in Figure 4, the redder fluorescence was observed in the cytoplasm of $\mathrm{HaCaT}$ cells incubated with RhB-NLC-R11 at $2 \mathrm{~h}$ than in the cytoplasm of RhBNLC. The HaCaT cells incubated with RhB-NLC-(0.02\%) R11 showed brighter florescence (red) than with other formulations, indicating that NLC modified with R11 at the ratio $(1: 1 \mathrm{w} / \mathrm{w})$ of DOGS-NTA-Ni to R11 peptide showed enhanced cellular permeability. The results were consistent with the quantitative uptake measurements of FCM. Therefore, NLC-R11 is expected to be a suitable system to deliver LN to the post stratum corneum with enhanced cellular uptake.

\section{Study of the mechanism of RII as a penetration enhancer Effects of LN-NLC and LN-NLC-RII on the membrane potential of $\mathrm{HaCaT}$ cells}

The HaCaT cell line derived from the human abdominal epidermis is an important model to study the human skin and is used widely as a substitute for normal human epidermal keratinocytes. The membrane potential plays a key role in the biophysical characteristics of the cell membrane, maintaining the balance of the ion concentration between the inside and outside of the cells. In general, the membrane potential changed accompanied by the change in the membrane permeability and structure of the membrane lipid and protein. ${ }^{42-44}$

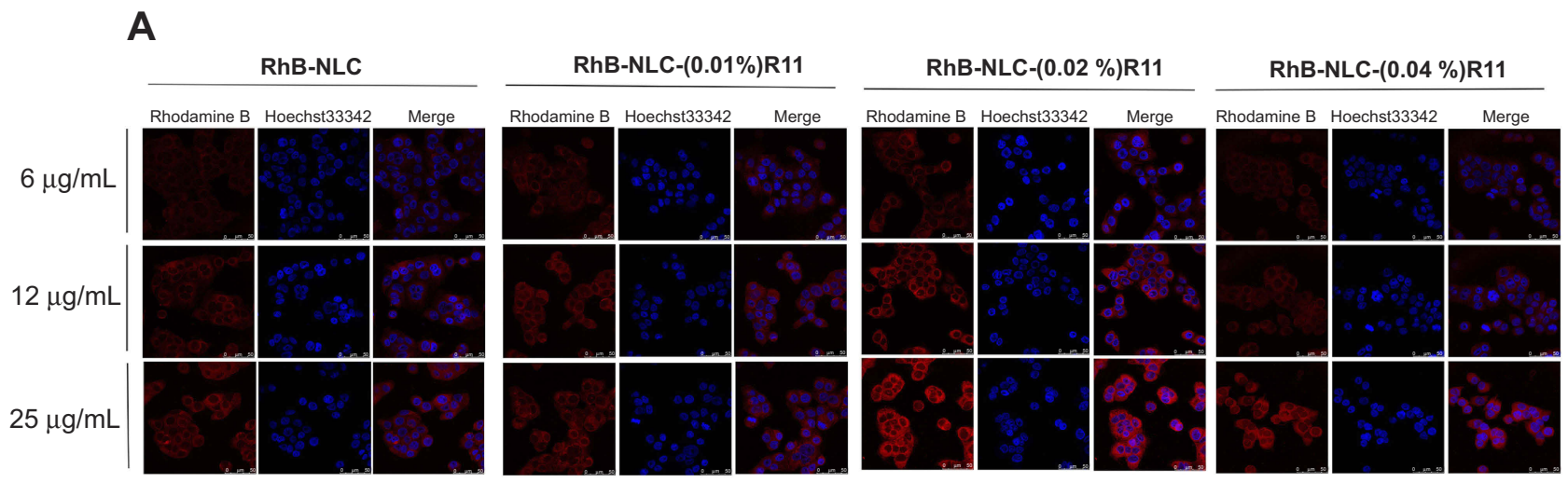

B

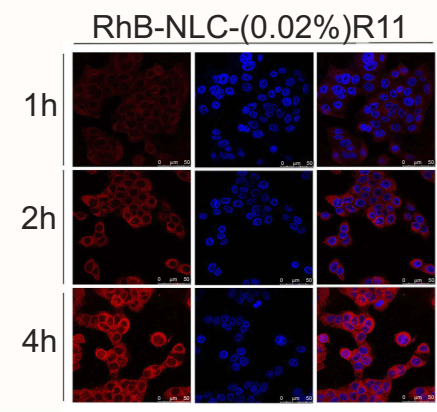

Figure 4 Confocal laser scanning microscopy images of $\mathrm{HaCaT}$ cells incubated with different formulations with various concentrations (A) and incubated with RhB-NLCRII in different time $(\mathbf{B})$. 
As shown in Figure 5, the mean fluorescence intensity of cells treated with LN-NLC-R11 was higher than that in cells treated with LN-NLCs, indicating that LN-NLC-R11 significantly decreased the membrane potential of $\mathrm{HaCaT}$ cells compared with LN-NLC. The negative charge inside the cell membrane and positive charge outside the cell membrane are maintained in the resting state. Nanoparticles could induce depolarization of the membrane when acting on the cell membrane. The more fluorescent probe DiBAC4 (3) with a negative charge could be transported across the membrane with increased depolarization of the membrane, leading to a decreased membrane potential. Furthermore, the decrease in the membrane potential is beneficial for nanoparticles to penetrate the cell membrane.

\section{Change in the intracellular $\mathrm{Ca}^{2+}$ concentration induced by RII}

Figure 5 shows significant enhancement of the intracellular fluo-3 fluorescence in cells incubated with LN-NLC$\mathrm{R} 11$, reflecting the corresponding increased $\mathrm{Ca}^{2+}$ concentration compared with cells cultured with LN-NLCs, indicating that R11 may enhance the permeability of cell membranes via changing the degree of intercellular $\mathrm{Ca}^{2+}$ concentration. Particularly, intercellular $\mathrm{Ca}^{2+}$ is a crucial second messenger that regulates signal transduction and other intracellular processes. Changes in the intracellular $\mathrm{Ca}^{2+}$ concentration could induce changes in the potential, fluidity and degree of tight junctions of the cell membrane, further influencing some cellular processes, such as endocytosis and micropinocytosis. ${ }^{45}$

\section{In vitro skin permeation of nanoparticles}

The results in Figure 6 show the effect of the surface modification of NLC on the skin permeation of LN. LNNLC-R11 significantly increased the cumulative penetration amount and skin deposition of LN $(P<0.01$ or $P<0.05)$ compared with LN-NLC alone. The cause may be due to the interaction of the positive charge in R11 with the negative charge in lipids and residues of proteins of SC, further inducing the destabilization of the lipid bilayer and membrane and leading to enhanced permeation of NLCs. ${ }^{46}$ Furthermore, the negatively charged NLCs obtained in this study showed less affinity to the skin. After modified with polyarginine peptides, the zeta potential was reduced to $-14 \mathrm{mV}$ from $-30 \mathrm{mV}$, which induced an increased affinity of the nanoparticles to the skin. Additionally, similar results were concluded in other studies. ${ }^{47,48}$ It was also found that CPP-conjugated nanoparticles penetrate through the skin by some appendages such as hair follicles and sebaceous glands. ${ }^{49}$ Although the enhanced permeation ability of CPPs is achieved by various pathways, such as diffusion through intercellular lipids and skin appendages, the amount of CPPs modified on NLCs could influence the permeating efficiency. As shown in Figure $6 \mathrm{~A}$ and B, especially with LN-NLC modified with $0.02 \%$ (w/w) R11, the cumulative penetration amount and retention in skin of LN was approximately 2.0 and 1.7 times higher than that with LN-NLC alone, respectively, indicating the greater enhanced permeation effect than with LNNLC modified with $0.01 \%(\mathrm{w} / \mathrm{w})$ R11 and $0.04 \%(\mathrm{w} / \mathrm{w})$ R11. The cause may be that the redundant R11 had no

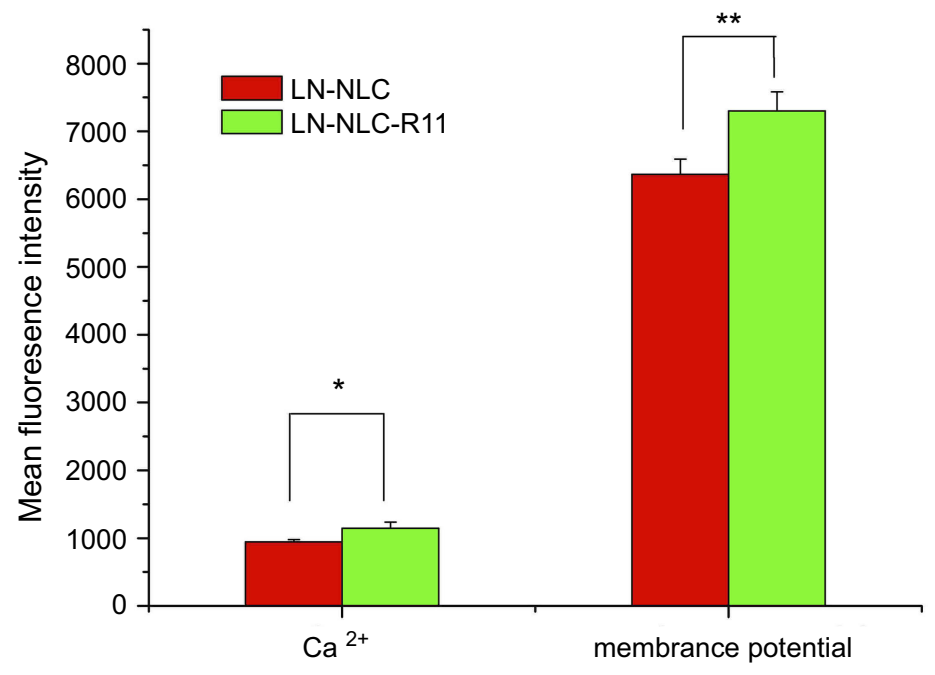

Figure 5 The results of $\mathrm{Ca}^{2+}$ concentration and membrane potential in $\mathrm{HaCaT}$ cells. Notes: Data presented as mean $\pm S D(n=3)$. $* P<0.05$, **P<0.0I. 

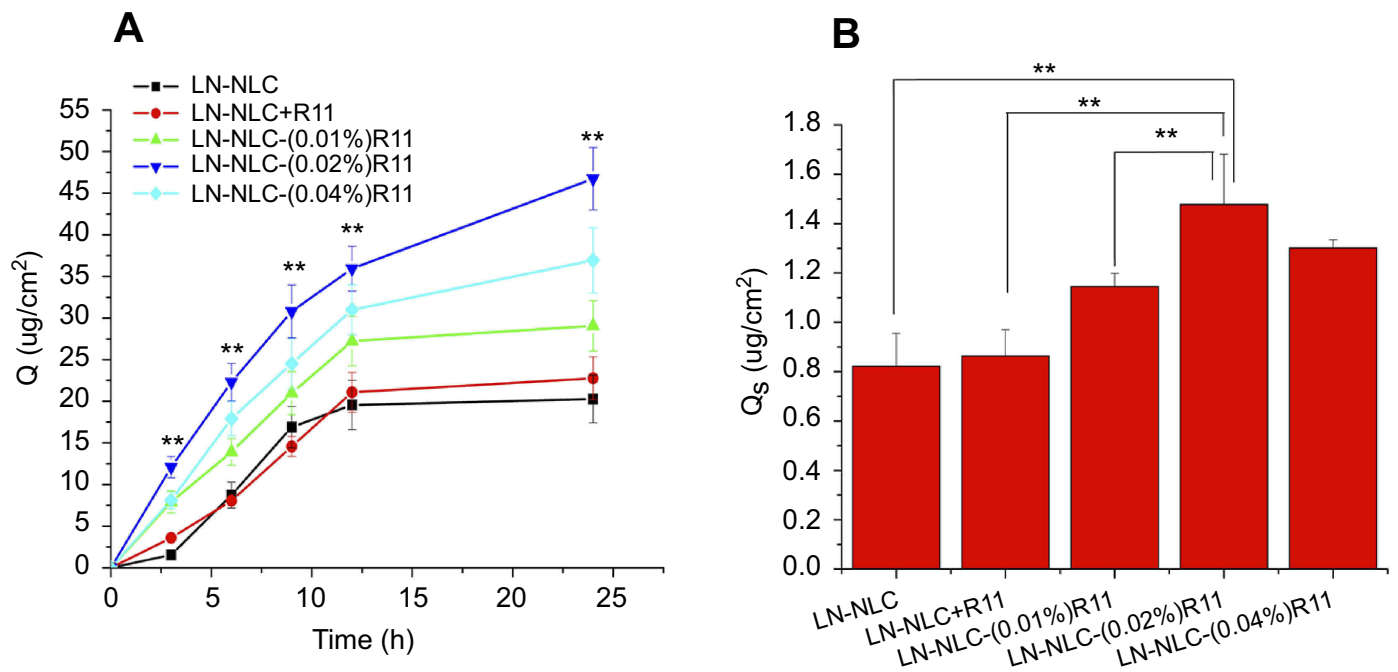

Figure 6 In vitro percutaneous permeability and retention in skin of LN.

Notes: (A) In vitro cumulative penetration amounts of lornoxicam per $\mathrm{cm}^{2}(Q)$ versus time profiles in different formulations, $* * P<0.0$ I, compared $L N-N L C$; (B) The skin drug deposition $\left(Q_{s}\right)$ of different formulations in transdermal permeation, $* * p<0.01$. Data presented as mean $\pm S D(n=3)$.

binding affinity to the surface of NLCs, limiting the space in which the nanoparticles penetrate the skin. Furthermore, NLCs prepared without DOGS-NTA-Ni in the presence of six histidine-tagged polyarginine peptides did not significantly increase the amount of $\mathrm{LN}$ in or through skin, indicating that no nonspecific interaction occurred between the nanoparticles and six histidine-tagged polyarginine peptides. Thus, NLCs prepared with $0.02 \%(\mathrm{w} / \mathrm{w}) \mathrm{R} 11$ and DOGS-NTA-Ni (R11:DOGS-NTA-Ni=1:1, w/w) allowed NLCs to penetrate the skin, leading to the maximum skin permeation of LN.

\section{Skin irritation evaluation}

In the skin irritation test, no erythema and edema were observed in rabbits, the mean irritation index was 0 , and no difference was found between the left side and right side of hairless skin. Thus, LN-NLC-R11 gels exhibited no irritation for topical application and will be safe for patients.

\section{Anti-inflammatory effect of the formulations of LN \\ Carrageenan-induced rat paw edema}

To evaluate the anti-inflammation effect of various formulations of LN, the carrageenan-induced paw edema method was adopted, and the results are presented in Figure 7A. As shown in Figure 7 (A), carrageenan-induced edema was alleviated significantly after the administration of LN-NLC gels (D) and LN-NLC-R11 gels (E) at the dosage of $2 \mathrm{mg} / \mathrm{kg}$ compared with blank NLC gels (A) and LN gels (C), respectively
( $P<0.05$ or $P<0.01$ ), demonstrating the good activity of NLC as the $\mathrm{LN}$ carrier in inhibiting acute inflammation.

Moreover, LN-NLC-R11 (E) gels ( $2 \mathrm{mg} / \mathrm{kg}$ of LN) significantly inhibited the paw edema of rats compared with LN-NLC gels (D) (2 $\mathrm{mg} / \mathrm{kg}$ of LN) at various time points $(\mathrm{P}<0.01)$, indicating that the cell-penetrating peptide R11 on the surface of LN-NLCs increased the local drug concentration by enhancing the percutaneous permeability of LN-NLCs, leading to an obvious anti-inflammatory effect. Additionally, inhibition of the paw edema of LNNLC-R11 (E) gels was higher than that of diclofenac sodium gels (B) during severe inflammation (3 h-5 h, $\mathrm{P}<0.05)$ and was similar to that during other periods, indicating the excellent anti-inflammatory effects of LNNLC-R11 (E) gels. Moreover, with the extension of time, especially 5 to $7 \mathrm{~h}$ after inflammation, LN-NLC-R11 gels (E) manifested sustained inhibition of paw edema, showing that LN-NLC-R11 gels not only promoted drugs through the skin but also extended the action time of drugs to achieve an anti-inflammatory effect in $7 \mathrm{~h}$. The edema degree, edema percentage and inhibitory rate of edema were calculated as follows:

$$
\text { Edema degree }=\mathrm{V}_{\text {right }}-\mathrm{V}_{\text {left }}
$$

Edema percentage $=\left(\mathrm{V}_{\text {right }}-\mathrm{V}_{\text {left }}\right) / \mathrm{V}_{\text {left }} \times 100 \%$

Inhibitory rate of edema $=\left(\mathrm{E}_{\mathrm{A}}-\mathrm{E}_{\text {test }}\right) / \mathrm{E}_{\mathrm{A}} \times 100 \%$

Where $V_{\text {right }}$ is the mean volume of the right hind paw, $V_{\text {left }}$ is the mean volume of left hind paw, $E_{\mathrm{A}}$ is the mean 
A

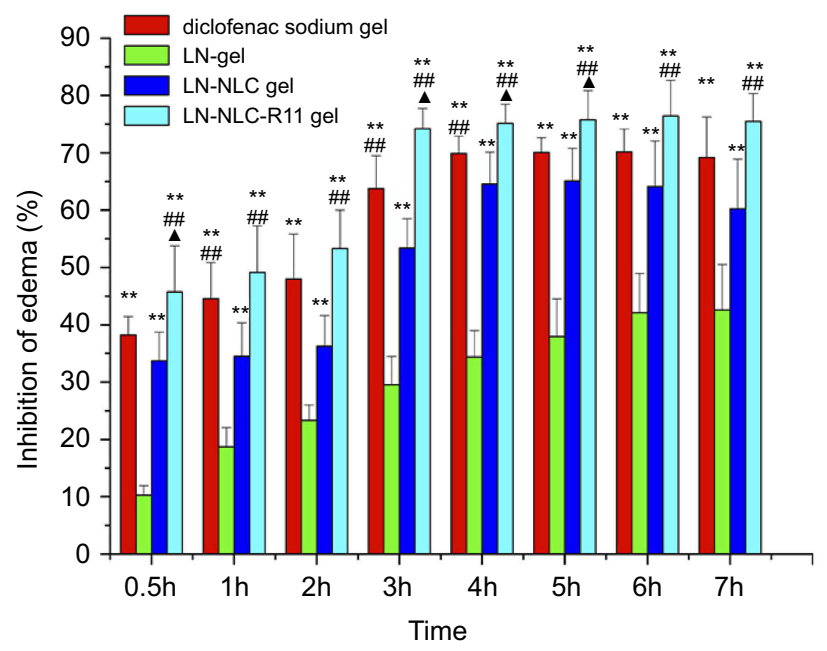

C

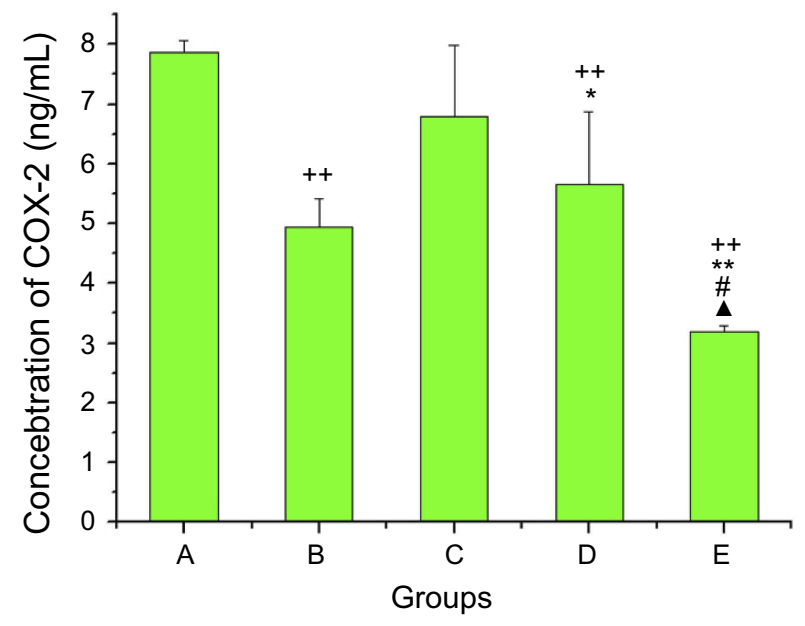

B

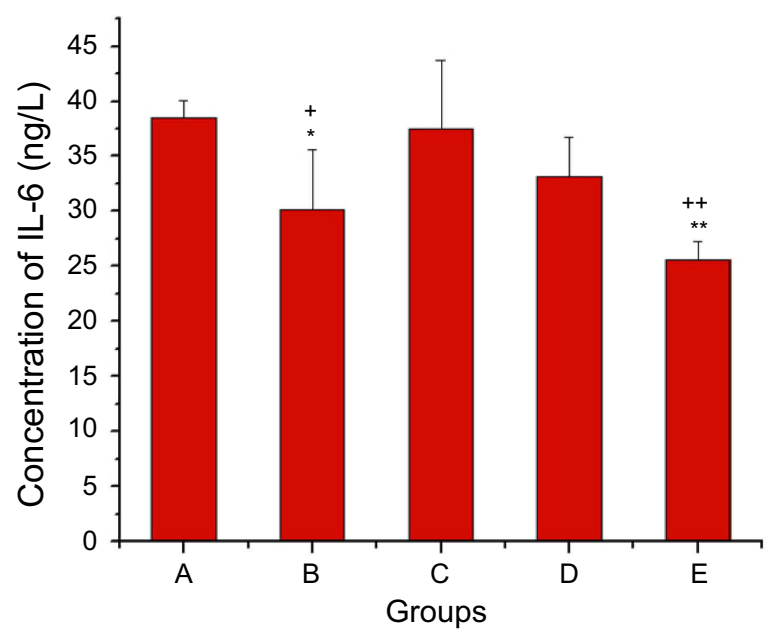

D

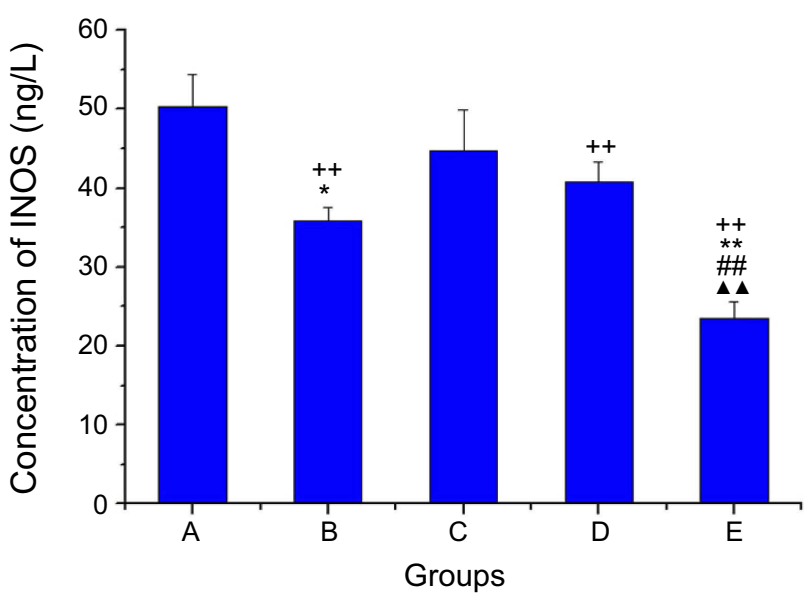

Figure 7 Anti-inflammatory activity tested by carrageenan-induced paw edema.

Notes: (A) The inhibition of various formulations on carrageenan-induced paw dema in rats. $\left(* * P<0.01\right.$, as compared to $L N$-gel; ${ }^{\#} P<0.01$, as compared to LN-NLC gel; $\triangle P<0.05$, as compared to diclofenac sodium gel). (B-D) The inhibition of various formulations on pro-inflammatory cytokine and chemokines (IL-6, COX-2, INOS) content in

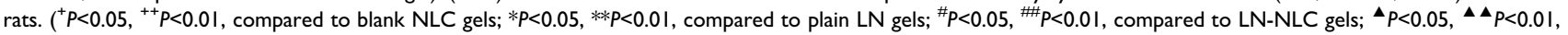
compared to diclofenac sodium gels). A: blank NLC gels (negative control); B: diclofenac sodium gels (positive control); C: plain LN gels; D: LN-NLC gels; E: LN-NLC-RI I gels. Data presented as mean \pm SD $(n=8)$.

edema percentage of negative control (group A) and $E_{\text {test }}$ is the mean edema percentage of test groups (B, C, D and E).

\section{Estimation of pro-inflammatory cytokines and chemokines in rat serum}

As a nonsteroidal anti-inflammatory drug (NSAID), LN reduces swelling in inflamed tissues. ${ }^{50}$ The principal mechanism of its action is via the inhibition of prostaglandin synthesis, which is mediated by the enzyme COX in the arachidonic acid pathway. ${ }^{51,52}$ The COX isoform COX-2 is produced during inflammation, resulting in the formation of excessive prostaglandins. Moreover, other inflammatory mediators such as reactive oxygen products and cytokines have been found to considerably induce inflammation. ${ }^{53,54}$ The overexpression of inducible nitric oxide synthase (iNOS) results in the increase of nitric oxide (NO) in inflamed tissues, further inducing edema in inflammatory sites. ${ }^{55}$ Among the pro-inflammatory cytokines, interleukin (IL)-6, which is relevant to the formation of inflammatory mediators, could be effectively reduced by $\mathrm{LN}^{50}$ As the well-established inflammatory cytokine and enzymes, serum IL-6, COX-2 and INOS play crucial roles in the pathology of inflammation and are determined to assess the degree of inflammation. ${ }^{56,57}$ 
Therefore, the effect of the developed different formulations in reducing inflammatory symptoms was investigated by determining markers such as IL-6, COX-2 and INOS in this study.

Figure 7B-D shows the levels of IL-6, COX-2 and INOS in the rat serum of different formulations, respectively. Significant decreases in the serum levels IL-6, COX-2 and INOS in rat models were observed after the administration of LN-NLC-R11 gels (E) compared with those in the negative control $(\mathrm{P}<0.01)$ and $\mathrm{LN}$ gels $(\mathrm{P}<0.01)$ in Figure $7 \mathrm{~B}-\mathrm{D}$, indicating that LN-NLC-R11 gels could effectively alleviate the severity of inflammation by reducing the serum content of inflammatory cytokines and relevant enzymes-ie, IL-6, COX-2 and INOS. The serum COX-2 and INOS levels of LN-NLC gels were significantly different from those of the negative control $(\mathrm{P}<0.01)$, although no significant differences were found in the serum IL-6 level among the negative control, LN gels and LN-NLC gels. LN-NLC-R11 gels showed no significant difference from the marketed product (diclofenac sodium gels) at the serum IL-6 level but showed a higher inhibition effect than the marketed product at the serum COX-2 and INOS levels $(\mathrm{P}<0.05$ or $\mathrm{P}<0.01)$, indicating their excellent effect treat inflammation.

\section{Conclusion}

The present study suggested that LN-NLCs were prepared successfully by an emulsion-evaporation and low temperature solidification method and were characterized by an appropriate size, high entrapment efficiency and drug loading. To enhance the transdermal permeability of LN, R11 was used in the formulation to prepare LN-NLC-R11. FCM and CLSM studies suggested that the NLC modified with R11 $(0.02 \%$, w/ w) had enhanced cell internalization of nanoparticles. The results of the in vitro permeation study demonstrated that LN-NLCs modified with $0.02 \%$ R11 exhibited favorable skin permeation and deposition in the skin by increasing the amount of $\mathrm{LN}$ penetrated through the skin and retained in skin layers, a condition that was favorable for topical application. Additionally, HPMC was used to prepare LN-NLC-R11 gels for the in vivo anti-inflammatory study. In the carrageenaninduced rat paw edema model, LN-NLC-R11 gels inhibited obviously rat paw edema and produced inflammatory cytokines compared with LN-NLC gels and LN gels. Thus, LNNLC gels containing the cell-penetrating peptide R11 developed in our study enhanced the translocation of LN across the skin, thereby alleviating the severity of inflammation and making it a promising preferred formulation of LN.

\section{Acknowledgments}

This work was financially supported by Shandong Provincial Natural Science Foundation (ZR2014HL104, ZR2016HP15) and National Natural Science Foundation of China (81703717).

\section{Disclosure}

The authors report no conflicts of interest in this work.

\section{References}

1. Balfour JA, Fitton A, Barradell LB. Lornoxicam. A review of its pharmacology and therapeutic potential in the management of painful and inflammatory conditions. Drugs. 1996;51(4):639-657. doi:10.2165/00003495-199651040-00008

2. Meineke I, Turck D. Population pharmacokinetic analysis of meloxicam in rheumatoid arthritis patients. Br J Clin Pharmacol. 2003;55 (1):32-38. doi:10.1046/j.1365-2125.2003.01753.x

3. Herrmann WA, Geertsen MS. Efficacy and safety of lornoxicam compared with placebo and diclofenac in acute sciatica/lumbo-sciatica: an analysis from a randomised, double-blind, multicentre, parallel-group study. Int $J$ Clin Pract. 2009;63(11):1613-1621. doi:10.1111/j.1742-1241.2009.02187.x

4. Lin SZ, Wouessidjewe D, Poelman MC, Duchêne D. In vivo evaluation of indomethacin/cyclodextrin complexes gastrointestinal tolerance and dermal anti-inflammatory activity. Int $J$ Pharm. 1994;106 (1):63-67. doi:10.1016/0378-5173(94)90276-3

5. Yener G, Üner M, Gönüllü Ü, et al. Design of meloxicam and lornoxicam transdermal patches: preparation, physical characterization, ex vivo and in vivo studies. Chem Pharm Bull. 2010;58(11):1466-1473.

6. Kavitha K, Rajendra MM. Design and evaluation of transdermal films of lornoxicam. Int J Pharma Bio Sci. 2011;2(2):54-62.

7. Ascenso A, Raposo S, Batista C, et al. Development, characterization, and skin delivery studies of related ultradeformable vesicles: transfersomes, ethosomes, and transethosomes. Int J Nanomedicine. 2015;10:5837-5851. doi:10.2147/IJN.S86186

8. Gönüllü Ü, Üner $M$, Yener $G$, Karaman EF, Aydoğmuş Z Formulation and characterization of solid lipid nanoparticles, nanostructured lipid carriers and nanoemulsion of lornoxicam for transdermal delivery. Acta Pharmaceutica. 2015;65(1):1-13. doi:10.1515/ acph-2015-0009

9. Al-Suwayeh SA, Taha EI, Al-Qahtani FM, Ahmed MO, Badran MM. Evaluation of skin permeation and analgesic activity effects of carbopol lornoxicam topical gels containing penetration enhancer. Sci World J. 2014;2014(2):127495. doi:10.1155/2014/127495

10. Abdel-Mottaleb MM, Neumann D, Lamprecht A. Lipid nanocapsules for dermal application: a comparative study of lipid-based versus polymer-based nanocarriers. Eur J Pharm Biopharm. 2011;79 (1):36-42. doi:10.1016/j.ejpb.2011.04.009

11. Karande P, Jain A, Mitragotri S. Insights into synergistic interactions in binary mixtures of chemical permeation enhancers for transdermal drug delivery. J Control Release. 2006;115(1):85-93. doi:10.1016/j. jconrel.2006.07.001

12. Barry BW. Mode of action of penetration enhancers in human skin. J Control Release. 1987;6(1):85-97. doi:10.1016/0168-3659(87) 90066-6

13. Murthy SN, Sammeta SM, Bowers C. Magnetophoresis for enhancing transdermal drug delivery: mechanistic studies and patch design. J Control Release. 2010;148(2):197-203. doi:10.1016/j.jconrel.2010.08.015

14. Henchoz Y, Abla N, Veuthey JL, Carrupt PA. A fast screening strategy for characterizing peptide delivery by transdermal iontophoresis. J Control Release. 2009;137(2):123-129. doi:10.1016/j. jconrel.2009.03.018 
15. Chen $\mathrm{H}$, Zhu H, Zheng J, et al. Iontophoresis-driven penetration of nanovesicles through microneedle-induced skin microchannels for enhancing transdermal delivery of insulin. $J$ Control Release. 2009;139(1):63-72. doi:10.1016/j.jconrel.2009.05.031

16. Vanbever R, Langers G, Montmayeur S, Préat V. Transdermal delivery of fentanyl: rapid onset of analgesia using skin electroporation. $J$ Control Release. 1998;50(1-3):225-235.

17. Bal SM, Kruithof AC, Zwier R, et al. Influence of microneedle shape on the transport of a fluorescent dye into human skin in vivo. J Control Release. 2010;147(2):218-224. doi:10.1016/j.jconrel.2010.07.104

18. Hou D, Xie C, Huang K, Zhu C. The production and characteristics of solid lipid nanoparticles (SLNs). Biomaterials. 2003;24 (10):1781-1785.

19. Wang JJ, Liu KS, Sung KC. Skin permeation of buprenorphine and its ester prodrugs from lipid nanoparticles: lipid emulsion, nanostructured lipid carriers and solid lipid nanoparticles. J. Microencapsul. 2009;26(8):734-747. doi:10.3109/02652040902746679

20. Pardeike J, Hommoss A, Müller RH. Lipid nanoparticles (SLN, NLC) in cosmetic and pharmaceutical dermal products. Int $J$ Pharm. 2009;366(1-2):170-184. doi:10.1016/j.ijpharm.2008.10.003

21. Lopes LB, Brophy CM, Furnish E, et al. Comparative study of the skin penetration of protein transduction domains and a conjugated peptide. Pharm Res. 2005;22(5):750-757. doi:10.1007/s11095-005-2591-x

22. Patlolla RR, Vobalaboina V. Pharmacokinetics and tissue distribution of etoposide delivered in parenteral emulsion. J Pharm Sci. 2005;94 (2):437-445. doi:10.1002/jps.20249

23. Jenning V, Schäferkorting M, Gohla S. Vitamin A-loaded solid lipid nanoparticles for topical use: drug release properties. J Control Release. 2000;66(3):115-126.

24. Bodade SS, Shaikh KS, Kamble MS, Chaudhari PD. A study on ethosomes as mode for transdermal delivery of an antidiabetic drug. Drug Deliv. 2013;20(1):40-46. doi:10.3109/10717544.2012.752420

25. Ammar HO, Ghorab M, Mahmoud AA, Makram TS, Noshi SH. Topical liquid crystalline gel containing lornoxicam/cyclodextrin complex. J Incl Phenom Macrocycl Chem. 2012;73(1-4):161-175. doi:10.1007/s10847-011-0039-y

26. Patel LN, Zaro JL, Shen WC. Cell penetrating peptides: intracellular pathways and pharmaceutical perspectives. Pharm Res. 2007;24 (11):1977-1992. doi:10.1007/s11095-007-9303-7

27. Desai P, Patlolla RR, Singh M. Interaction of nanoparticles and cellpenetrating peptides with skin for transdermal drug delivery. Mol Membr Biol. 2010;27(7):247-259. doi:10.3109/09687688.2010.522203

28. Cohenavrahami M, Aserin A, Garti N. H(II) mesophase and peptide cell-penetrating enhancers for improved transdermal delivery of sodium diclofenac. Colloids Surf B Biointerfaces. 2010;77(2):131138. doi:10.1016/j.colsurfb.2010.01.013

29. Cohenavrahami M, Libster D, Aserin A, Garti N. Sodium diclofenac and cell-penetrating peptides embedded in HII mesophases: physical characterization and delivery. J Phys Chem B. 2011;115(34):1018910197. doi:10.1021/jp112067v

30. Rao S, Barot T, Rajesh KS, Jha LL. Formulation, optimization and evaluation of microemulsion based gel of Butenafine Hydrochloride for topical delivery by using simplex lattice mixture design. J. Pharm Investig. 2016;46(1):1-12. doi:10.1007/s40005-015-0207-y

31. Zeb A, Qureshi OS, Yu CH, et al. Enhanced anti-rheumatic activity of methotrexate-entrapped ultradeformable liposomal gel in adjuvantinduced arthritis rat model. Int $J$ Pharm. 2017;525(1):92-100. doi:10.1016/j.ijpharm.2017.04.032

32. Schousboe A, Frandsen A, Krogsgaard-Larsen P. Pharmacological and functional characterization of excitatory amino acid mediated cytotoxicity in cerebral cortical neurons. Cell Biol Toxicol. 1992;8 (3):93-100.

33. Liu W, Teng L, Yu K, et al. Design of hydrogels of 5-hydroxymethyl tolterodine and their studies on pharmacokinetics, pharmacodynamics and transdermal mechanism. Eur J Pharm Sci. 2017;96:530-541. doi:10.1016/j.ejps.2016.10.024
34. Shrotriya S, Ranpise N, Satpute P, Vidhate B. Skin targeting of curcumin solid lipid nanoparticles-engrossed topical gel for the treatment of pigmentation and irritant contact dermatitis. Artif Cells Nanomed Biotechnol. 2018;46(7):1471-1482. doi:10.1080/ 21691401.2017.1373659

35. Ng SF, Tan LS, Buang F. Transdermal anti-inflammatory activity of bilayer film containing olive compound hydroxytyrosol: physical assessment, in vivo dermal safety and efficacy study in Freund's adjuvantinduced arthritic rat model. Drug Dev Commun. 2017;43(1):108-119.

36. Nakamura Y, Kogure K, Futaki S, Harashima H. Octaarginine-modified multifunctional envelope-type nano device for siRNA. J Control Release. 2007;119(3):360-367. doi:10.1016/j.jconrel.2007.03.010

37. Kang MH, Park MJ, Yoo HJ, et al. RIPL peptide (IPLVVPLRRRRRRRRC)-conjugated liposomes for enhanced intracellular drug delivery to hepsin-expressing cancer cells. Eur J Pharm Biopharm. 2014;87(3):489-499. doi:10.1016/j.ejpb.2014.03.016

38. Verma P, Pathak K. Nanosized ethanolic vesicles loaded with econazole nitrate for the treatment of deep fungal infections through topical gel formulation. Nanomedicine. 2012;8(4):489-496. doi:10.1016/j. nano.2011.07.004

39. Din FU, Mustapha O, Kim DW, et al. Novel dual-reverse thermosensitive solid lipid nanoparticle-loaded hydrogel for rectal administration of flurbiprofen with improved bioavailability and reduced initial burst effect. Eur J Pharm Biopharm. 2015;94:64-72. doi:10.1016/j.ejpb.2015.04.019

40. Jaiswal M, Kumar A, Sharma S. Nanoemulsions loaded Carbopol ${ }^{\circledR} 934$ based gel for intranasal delivery of neuroprotective Centella asiatica extract: in-vitro and ex-vivo permeation study. J Pharm Investig. 2016;46(1):79-89. doi:10.1007/s40005016-0228-1

41. Kaur L, Jain SK, Singh K. Vitamin E TPGS based nanogel for the skin targeting of high molecular weight anti-fungal drug: development and in vitro and in vivo assessment. RSC Adv. 2015;5 (66):53671-53686. doi:10.1039/C5RA08374E

42. Zbytovská J, Raudenkolb S, Wartewig S, et al. Phase behaviour of transkarbam 12. Chem Phys Lipids. 2004;129(1):97-109. doi:10.1016/j.chemphyslip.2003.12.004

43. Thanou M, Florea BI, Langemeÿer MWE, Verhoef JC, Junginger HE. $\mathrm{N}$-trimethylated chitosan chloride (TMC) improves the intestinal permeation of the peptide drug buserelin in vitro (Caco-2 cells) and in vivo (Rats). Pharm Res. 2000;17(1):27-31.

44. Thanou MM, Kotzé AF, Scharringhausen T, et al. Effect of degree of quaternization of $\mathrm{N}$-trimethyl chitosan chloride for enhanced transport of hydrophilic compounds across intestinal caco-2 cell monolayers. J Control Release. 2000;64(3):15-25.

45. Yang F, Zhang M, He W, et al. Controlled release of $\mathrm{Fe}_{3} \mathrm{O}_{4}$ nanoparticles in encapsulated microbubbles to tumor cells via sonoporation and associated cellular bioeffects. Small. 2011;7(7):902-910. doi:10.1002/smll.201002185

46. Patlolla RR, Desai P, Belay K, Singh M. Translocation of cell penetrating peptide engrafted nanoparticles across skin layers. Biomaterials. $\quad 2010 ; 31(21): 5598-5607 . \quad$ doi:10.1016/j. biomaterials. 2010.03 .010

47. Jung S, Otberg N, Thiede G, et al. Innovative liposomes as a transfollicular drug delivery system: penetration into porcine hair follicles. J Invest Dermatol. 2006;126(8):1728-1732. doi:10.1038/sj.jid.5700323

48. Song YK, Kim CK. Topical delivery of low-molecular-weight heparin with surface-charged flexible liposomes. Biomaterials. 2006;27(2):271-280. doi:10.1016/j.biomaterials.2005.05.097

49. Knorr F, Lademann J, Patzelt A, Sterry W, Blumepeytavi U, Vogt A. Follicular transport route-research progress and future perspectives. Eur J Pharm Biopharm. 2009;71(2):173-180. doi:10.1016/j.ejpb.2008.11.001

50. Berg J, Fellier H, Christoph T, Grarup J, Stimmeder D. The analgesic NSAID lornoxicam inhibits cyclooxygenase (COX)-1/-2, inducible nitric oxide synthase (iNOS), and the formation of interleukin (IL)-6 in vitro. Inflamm Res. 1999;48(7):369-379. doi:10.1007/s000110050474 
51. Smith WL, Marnett LJ. Prostaglandin endoperoxide synthase: structure and catalysis. Biochim Biophys Acta. 1991;1083(1):1-17. doi:10.1016/0005-2760(91)90119-3

52. Smith WL. Prostanoid biosynthesis and mechanisms of action. Am J Physiol. 1992;263(2):181-191.

53. Watkins LR, Maier SF, Goehler LE. Immune activation: the role of pro-inflammatory cytokines in inflammation, illness responses and pathological pain states. Pain. 1995;63(3):289-302.

54. Anbar M, Gratt BM. Role of nitric oxide in the physiopathology of pain. J Pain Symptom Manage. 1997;14(4):225-254.
55. Feldmann M, Brennan FM, Maini RN. Role of cytokines in rheumatoid arthritis. Annu Rev Immunol. 1996;14(11):397-440. doi:10.1146/ annurev.immunol.14.1.397

56. Mello SBV, Barros DM, Silva ASF, Laurindo IMM, Novaes GS. Methotrexate as a preferential cyclooxygenase 2 inhibitor in whole blood of patients with rheumatoid arthritis. Rheumatology. 2000;39 (5):533-536. doi:10.1093/rheumatology/39.5.533

57. Choy EH, Panayi GS. Cytokine pathways and joint inflammation in rheumatoid arthritis. $N$ Engl J Med. 2001;344(12):907-916. doi:10.1056/NEJM200103223441207

\section{Publish your work in this journal}

The International Journal of Nanomedicine is an international, peerreviewed journal focusing on the application of nanotechnology in diagnostics, therapeutics, and drug delivery systems throughout the biomedical field. This journal is indexed on PubMed Central, MedLine, CAS, SciSearch ${ }^{\circledR}$, Current Contents ${ }^{\circledR} /$ Clinical Medicine, $^{-}$
Journal Citation Reports/Science Edition, EMBase, Scopus and the Elsevier Bibliographic databases. The manuscript management system is completely online and includes a very quick and fair peer-review system, which is all easy to use. Visit http://www.dovepress.com/ testimonials.php to read real quotes from published authors. 